\title{
ESPECIAL
}

\section{A PROFISSÃO DOCENTE E O CUIDADO COM A VIDA}

\author{
Antônio Joaquim Severino ${ }^{1}$
}

\begin{abstract}
RESUMO: O ensaio desenvolve o argumento de que a profissão docente se justifica e se legitima, em última instância, pela sua condição de prática de cuidado com a vida². Partindo da premissa de que toda prática profissional tem seu sentido último no cuidado com a vida humana, defende a ideia de que, a prática docente é, em máximo grau, compromissada e responsável por esse cuidar, uma vez que a educação, por ela mediada, tem por destinação intrínseca a implementação do projeto antropológico de constituição do humano no homem. Ao investir no esclarecimento do sentido e na consolidação das relações práticas construtivas do sujeito humano com a natureza, com a sociedade e com a cultura simbólica, a educação, em todas as suas formas e particularmente em sua modalidade institucionalizada, visa contribuir de modo intencional e sistemático, para a formação do homem que emerge, incompleto e frágil, em sua condição de ser imanente à natureza. Por isso, a prática profissional do educador, assim como todas as práticas de outras carreiras profissionais, significa empenho em propiciar, no espaço social e no tempo histórico, cuidado com a vida dos educandos, ao investir em sua formação integral de modo que possam ter uma existência com maior e melhor qualidade de vida.

Palavras-chave: Profissão. Cuidado com a vida. Profissão docente. Formação profissional. Formação de professores.
\end{abstract}

${ }^{1}$ Bacharel e mestre em Filosofia pela Universidade Católica de Louvain, Bélgica. Doutor em Filosofia pela PUC de São Paulo. Livre-docente em Filosofia da Educação pela USP. Professor titular de Filosofia da Educação, ora aposentado, da Faculdade de Educação da USP. Atualmente trabalha no Programa de Pós-Graduação em Educação, da Uninove, em São Paulo.E-mail: ajsev@uol.com.br.

20 presente ensaio foi a base da palestra apresentada como a aula inaugural do Programa de Pós-Graduação em Educação da Universidade do Vale do Sapucaí - UNIVÁS, proferida no dia 15 de agosto de 2017. Ao mesmo tempo que, em decorrência dessa origem, ele mantenha um perfil de uma apresentação oral, foram retiradas do texto original as referências específicas daquela circunstância. Agradeço o espaço que a revista Argumento Pro-Educação abriu para ele, permitindo assim registar a memória do referido evento. 


\section{TEACHING PROFESSION AND CARE FOR LIFE}

ABSTRACT: The essay develops the argument that the teaching profession is justified and ultimately legitimized by its practice of caring for life. Based on the premise that all professional practice has its ultimate meaning in caring for human life, it defends the idea that, to the greatest extent, the teaching practice is committed and responsible for this care, since education, mediated by it, has as an intrinsic destination the implementation of the anthropological project of human constitution in man. By investing in the clarification of meaning and in the consolidation of the constructive practical relations of the human subject with nature, with society and with symbolic culture, education, in all its forms and particularly in its institutionalized modality, aims to contribute in an intentional and systematic, for the formation of the man who emerges, incomplete and fragile, in his condition of being immanent to nature. Therefore, the professional practice of the educator, as well as all the practices of other professional careers, means a commitment to foster, in social space and in historical time, care for the life of learners, by investing in their integral formation so that they can have an existence with a greater and better quality of life.

Keywords: Profession. Life care. Teaching profession. Professional qualification. Teacher training.

\section{PROFESIÓN DOCENTE Y EL CUIDADO CON LA VIDA}

RESUMEN: El ensayo desarrolla el argumento de que la profesión docente se justifica y se legitima, en última instancia, por su condición de práctica de cuidado con la vida. A partir de la premisa de que toda práctica profesional tiene su sentido último en el cuidado de la vida humana, defiende la idea de que la práctica docente es, en máximo grado, comprometida y responsable de ese cuidar, una vez que la educación, por ella mediada, tiene por destino intrínseca la implementación del proyecto antropológico de constitución de lo humano en el hombre. Al invertir en el esclarecimiento del sentido y en la consolidación de las relaciones prácticas constructivas del sujeto humano con la naturaleza, con la sociedad y con la cultura simbólica, la educación, en todas sus formas y particularmente en su modalidad institucionalizada, pretende contribuir de modo intencional y, sistemático, para la formación del hombre que emerge, incompleto y frágil, en su condición de ser inmanente a la naturaleza. Por eso, la práctica profesional del educador, así como todas las prácticas de otras carreras profesionales, significa empeño en propiciar, en el espacio social y en el tiempo histórico, cuidado con la vida de los educandos, al invertir en su formación integral de modo que puedan tener una existencia con mayor y mejor calidad de vida.

Palabras clave: Profesión. Cuidado con la vida. Profesión docente. Formación profesional. Formación de profesores. 


\section{Introdução}

Minha reflexão tem por tema o sentido da profissão docente como cuidado com a vida. Parto da premissa de que se toda profissão já é cuidado com a vida, a profissão docente o é em máximo grau até porque esta é a destinação da própria educação. Toda profissão, enquanto exercício de uma prática operativa na sociedade, tem sua razão de ser na prestação de um cuidado com a vida. A profissão docente, como todas as demais profissões, só se legitima porque ela é uma demanda de cuidado com a vida.

Bem entendido, estaremos tomando a expressão cuidado com a vida num sentido bem mais amplo e profundo do que naquele denotado pelo sentido da conservação da vida puramente biológica, como ressoa da forte associação com uma abordagem positivista, empirista mesmo, e que se visibiliza para o senso comum por meio, particularmente, das práticas médicas e das práticas específicas dos cuidados com a saúde. Obviamente esse sentido, pautado na abordagem positivista das ciências e das técnicas médicas, voltadas para a conservação da saúde, está envolvido e pressuposto em nossa concepção de cuidado com a vida. Mas ele está longe de esgotá-lo. Essa precaução não nos lança de cheio numa certa visão idealizante que privilegia a vida como mero processo de subjetivação que dilui a corporeidade numa subjetividade puramente desejante, processo que faz retornar a supremacia de uma transcendência sobre a nossa radical imanência.

\section{A vida precisa ser cuidada}

Mas por que é preciso ter cuidado com a vida? Porque a vida humana é um frágil caniço, exposto a ventos e tempestades. É o que nos mostra um breve percurso antropológico: a epopeia de nossa espécie, que só sobrevive em permanente e tenso equilíbrio.

De um primeiro vínculo, radicalmente dependente da natureza material. É uma dependência integral, em tempo real, e a cada instante. Daí a necessidade de bem conhecê-la para bem se lidar com ela, pois é dela que vem toda sustentação material da própria vida. Eis a lição da própria vida: somos feitos de matéria orgânica.

De um segundo ângulo, totalmente dependente da sociedade. Integral dependência em relação ao outro de nós. Somos separados e distintos, mas integralmente vinculados à sociedade que é como uma segunda placenta para nós. Aqui também existe um forte cordão umbilical. 
E, com igual vinculação, a vida depende de sua imersão na cultura. Estamos mergulhados no líquido amniótico da placenta cultural, sem a qual seríamos como pedras. E tudo que é relação ôntica precisa ser assegurado como se fosse um elemento componente do ser. Somos entretecidos cotidianamente.

\section{O homem no universo}

Um rápido percurso antropológico pode bem desvelar a epopeia de nossa espécie na superfície deste minúsculo planeta, onde sua continuidade depende de um permanente, tenso e frágil equilíbrio (BRANDÃO, 2015; CHARDIN, 1955; HARARI, 2017). Num primeiro momento, o real, ou seja, tudo aquilo que existia, foi uma imensa massa composta de matéria e energia, em íntima, contínua e forte interação. A energia é uma força que provoca movimento das partículas físicas que constituíam essa massa cósmica universal. Por que existia essa realidade? Não há resposta ao alcance de nossa capacidade de compreensão. Trata-se de então de um fato originário que nos impõe uma "objetividade", que é posta como um dado antecedente a tudo o mais. Tudo o que se pode colocar à nossa experiência, funda-se nessa realidade originante, cuja existência precede e de cuja origem pouco se pode falar. Por isso, já os filósofos antigos se punham a questão ontológica básica: por que algo existe de preferência ao nada?

Obviamente não cabe aqui desenvolver qualquer especulação a respeito. Esta breve referência é feita en passant à guisa de mera lembrança. Voltemos literalmente à terra.

Vivemos e existimos num pequeno fragmento desse todo, o planeta Terra, que faz parte de um conjunto maior, mas também ainda muito pequeno em relação ao todo, que é o sistema solar. Nossa história humana concentra-se basicamente nesse microssistema. $\mathrm{O}$ sol, fonte concentrada de energia, interagiu inicialmente com a matéria deste planeta, produzindo uma impressionante multiplicação e diferenciação das partículas, criando uma maravilhosa complexidade química, que constitui então os elementos da natureza material do planeta.

Mas eis que ao longo de uma imensurável duração temporal, essa interação entre os elementos materiais e as forças energéticas faz eclodir, na superfície do planeta, uma nova modalidade de ser, de expressão do existir, a vida, o processo orgânico, graças ao qual partículas materiais se unem, se estruturam e se organizam de forma extremamente diferenciada e ainda mais complexa, produzindo entes capazes de ação autônoma e de auto-reprodução. 


\section{[A emergência da biosfera]}

Forma-se assim uma nova camada que, como uma membrana envolvente, cobre toda a superfície do planeta, a biosfera. A vida explode e prolifera, sob uma igualmente impressionante diversidade de formas, por toda a terra. Novas formas de interação material e energética entre as partículas viabilizam o surgimento dos entes orgânicos que mobilizam segmentos de matéria e pulsos energéticos, o que thes permite destacada autonomia no seio da natureza. A vida se realiza então como um forte élan que parece visar sua própria continuidade mediante a reprodução e expansão, como que embutindo em si mesmas finalidades que passam a ser buscadas incessantemente. Mecanismos biológicos articulados a um embrionário sistema nervoso são impregnados de uma pulsão vital, designada como instinto, determinam e direcionam os modos de agir dos organismos vivos.

A biosfera é como que um tecido que emaranha todos os viventes e os articula com a natureza material. Ao mesmo tempo que se expande horizontalmente sobre a superfície do planeta como uma malha abrangente, vai ocorrendo também uma contínua complexificação e especialização das formas viventes, vegetais e animais, surgindo, ao longo do tempo, tipos diferenciados de indivíduos articulados em espécies igualmente diferenciadas. Esse é o fenômeno da evolução, mediante o qual os seres vivos vão se transformando, desde as formas mais simples até a formas cada vez mais complexas.

O que garante essa diferenciação é exatamente a formação de sistemas nervosos igualmente mais centralizados e sofisticados, aprimorando os recursos da sensibilidade instintiva dos indivíduos das diferentes espécies, configurando-se cada vez mais como sistemas cibernéticos, capazes de se auto organizar e de se auto reproduzir, se transformando e se complexificando.

Essa evolução, em sua dimensão filogenética, acaba levando as formas viventes à espécie humana, inaugurada com os primatas superiores, com um sistema nervoso já com avançada complexidade e capacidade ainda mais sofisticada. Essa espécie antropoide põe concretamente as condições para a emergência de uma nova capacidade que faz avançar e sofisticar ainda mais as interações vitais. Emerge uma nova forma de sensibilidade, a consciência, que instaura o território da subjetividade. Mediante a consciência os indivíduos da espécie adquirem como que um instinto mais poderoso, graças ao qual tornam-se capazes não apenas de agir pela pulsão instintiva, mas tomando consciência dos fins e dos meios de sua ação. Forma-se então uma nova camada que atravessa e impregna a espécie, a noosfera agregando-se à biosfera. Outro passo maravilhoso e admirável, mas 
igualmente difícil de ser explicado e entendido!

Desde os inícios temporais arcaicos, possíveis de serem retomados, ao longo dessa permanente interação entre matéria e energia, pode-se perceber que estão atuando processos imanentes que conduzem essas transformações, segundo leis intrínsecas, mas sempre agregando capacidades que transcendem esses próprios mecanismos. Como no caso da consciência: ela não pode ocorrer, como é obviamente evidente, sem a estrutura anatômica e fisiológica do cérebro, mas produz efeitos que não são decorrentes mecânicos desses processos. A questão está na dificuldade de se entender como ligações sinápticas podem ser geradoras de significações subjetivas.

Ou seja, quanto mais foi avançando o processo evolutivo, mais complexas foram ficando a estrutura orgânica e funcional dos seres vivos, caminhando rumo a essa fase de subjetivação, ou seja, os próprios processos naturais objetivos adquirem uma dimensão subjetivada, que passa a marcar, com significativa autonomia, as ações postas pelos entes vivos humanos.

\section{A vida em sua tríplice dimensão}

Nessa longa trajetória, tecida em permanente processo em que a ontogênese e filogênese se articulam, numa dinâmica dialética feita de avanços e recuos, a existência humana se afirma como processo vital que mergulha a espécie nesse fluxo e nessa teia de contradições. O homem é um ser natural, dotado de vida orgânica, compartilhada com todos os demais seres vivos. Avança em relação a eles ao dispor dos recursos da subjetivação que sofisticam e potencializam a sua capacidade para enfrentar os desafios da vida.

É que a característica marcante da pulsão da vida é o esforço para se manter. Enquanto pulsa, a vida insiste em se manter, em se prolongar e em se reproduzir. Não é diferente no caso da vida humana, mesmo sabendo o homem que está destinado à morte.

A vida humana se expressa então como sustentação, por meio das práticas relacionais - com a natureza, com os semelhantes e com os bens culturais, dessa pulsão vital, que só se mantém numa permanente situação de equilíbrio, estado de harmonia entre todos os elementos envolvidos. Pois a falta ou a agressão de qualquer um desses elementos representam ameaças à vida. Eis o que significam a fome, a sede, a doença bem como tantas outras formas de perda. Ao final, com a morte individual, a vida da espécie se sobrepõe à vida do indivíduo, a filogênese levando a melhor sobre a ontogênese.

Assim sendo, nossa existência é permanentemente dependente de um frágil equilíbrio de 
nossas relações com a natureza material, com os nossos parceiros nesse destino e com os elementos culturais que sustentam nossa experiência subjetiva. Vale dizer que a vida humana se desdobra num tríplice processo: sobrevivência, convivência e consciência. Está em pauta assegurar, da melhor maneira possível, o máximo de equilíbrio e harmonia em nossas relações com a natureza, com a sociedade e com a cultura. Mas nada disso é fácil.

Trata-se de uma condição extremamente contraditória, pois as forças que nos tornam mais humanizados são as mesmas que podem nos desumanizar, nos degradando, nos oprimindo e nos alienando. Tal condição de ambiguidade pode se expressar pelo fato de estarmos dilacerados entre o ser e o não-ser, entre o prazer e a dor. A vida, em sua plenitude de ser, é marcada pela experiência do prazer, do bem-estar, da felicidade, formas de expressarmos a experiência pela qual sentimos subjetivamente a vida; já quando ela é vivida sob o efeito de alguma carência ou agressão, ela se marca pela experiência da dor, do sofrimento, do mal-estar, da infelicidade e, no limite, pela morte. Eis o que significam a guerra, a violência e tantas outras formas concretas de perdas.

Em síntese, a vida de que se trata aqui não se reduz ao processo puramente biológico, imanente à pulsação natural do corpo orgânico. Sem dúvida, envolve essa dimensão pois ela é condicionante e fundamental, pois o ser humano é antes de tudo corpo, carne e sangue, sistema nervoso. A corporeidade é condição sine qua non de nossa existência. Mas a vida dos seres humanas envolve ainda mais duas dimensões: ela se encarna também num tecido social, pois não há como existir humanamente fora dessa rede de relações sociais, o indivíduo não pode ser considerado como humano separadamente do grupo.

A espécie é então atravessada por um modo de ser coletivo que the confere um coeficiente de sociabilidade em seu existir, que passa a integrar sua vida. Mas existir, para nós, implica ainda impregnar-se na placenta cultural, ou seja, estamos igualmente mergulhados e integrados a uma malha de significações simbólicas, geradas e alimentadas pelo exercício da subjetivação. Assim nosso modo de ser se trama no exercício simultâneo de um viver prático que nos envolve com a natureza, com a sociedade e com a cultura. Isso é tão real e denso, tão constitutivo que mal percebemos, tal a profundidade e a radicalicade dessa integração múltipla e complexa.

O sofrimento, a dor e a culpa são coetâneos da própria humanidade. Eles expressam o substancial da forma como a luta pela sobrevivência da espécie se configurou e se cristalizou, diferenciando o ser humano dos demais seres vivos. Nossa espécie foi privilegiada com o dispositivo da subjetividade para melhor cuidar de sua sobrevivência. Mas essa foi uma faca de dois gumes, pois 
essa subjetividade tornou-se também um verdadeiro espelho de nossa prática real. E por isso é sempre pago um preço muito elevado.

A história dos homens é o retrato vivo dessa contradição tal qual ela se espraia no tempo. 0 exercício dessa subjetividade que nos dotou de tão poderosos instrumentos, igualmente nos desnudou, mostrando nossa dura e crua realidade, da qual passamos a tomar consciência, como nos vendo refletidos num espelho. Muitos são os estratagemas dessa mesma subjetividade para se ocultar de si mesma, o que nos leva sempre à alienação, incapaz de nos livrar de nossa contingência. $E$ até hoje continuamos atravessados por essa contradição, buscando sempre utilizar essa que é, na verdade, nossa única ferramenta para realizar nossa aspirada condição de seres plenamente autônomos, livres e fraternos. Somos seres inacabados, incompletos, seres em devir, procurando no vir-a-ser um novo momento de realização.

O conhecimento é a principal ferramenta, se não a única, de que a espécie dispõe para buscar a adequada convivência com essa condição de fragilidade e de ambiguidade, ao elucidar o sentido de nossas práticas concretas pelas quais efetivamos nossas relações vitais. Mas ele pode também ser usado para o fim contrário, uma vez que ele se encontra também envolvido com as contradições que tornam ambíguo nosso modo real de existir.

Assim, a luta pela manutenção da vida e pela sobrevivência faz com que os homens entrem numa competição ferrenha entre si, usando os mesmos recursos diferenciados da subjetividade não só para otimizar os laços da solidariedade, mas também para o enfrentamento fratricida, investindo sistematicamente na destruição recíproca. Não bastassem as injunções da natureza (a fome, a doença, as intempéries, a debilitação física) eles são assolados também pelas injunções do convívio social [as guerras, as fraudes, as agressões de toda ordem]. Ao mesmo tempo que são intrinsecamente solidários, os homens são igualmente predadores uns dos outros.

Por isso, para que a vida humana sobreviva, ela precisa ser bem cuidada. O sentido fundamental da educação se encontra e se legitima no cuidado da vida humana, em sua múltipla e complexa fenomenalidade.

\section{Todas as carreiras profissionais são cuidadoras da vida}

Nosso existir vai se realizando pela mediação de nossas práticas concretas. A prática é, por sinal, o modo substantivo de nosso existir. Ao agir cotidianamente, relacionando-nos exatamente com 
os objetos que constituem a natureza, com os nossos semelhantes que compõem a sociedade e com as referências simbólicas que configuram a cultura, vamos expressando nosso modo de ser ao mesmo tempo que sustentando a continuidade da vida.

Por isso mesmo, podemos afirmar com toda segurança, que todas as carreiras, espaços de nossas atividades práticas profissionais, se entretecem nessa tríplice dimensionalidade envolvendo a natureza, a sociedade e a cultura. Assim, a finalidade de toda formação encontra-se na condução da existência concreta dos homens. A formação profissional está intimamente vinculada a essa destinação, mesmo naquelas áreas em que isto não transparece claramente. Muitas vezes, o cientista parece um indivíduo isolado do mundo, que vive fechado num laboratório ou então que vive fechado num universo teórico, mergulhado em abstrações. Mas isso é uma ilusão, pois tudo que se relaciona com a formação profissional tem a ver, e muito radicalmente, com o existir histórico das pessoas.

Dessas considerações acima relacionadas à condição do existir humano, pode-se constatar que todas as profissões e todos os conhecimentos, técnicas e valores nelas implicados têm a ver com o cuidado com a vida humana. Não sem razão se afirma hoje que o conhecimento é estratégia da vida e que nasce embutido na ação (REIS, 2015; SEVERINO, 2001, 2017).

Quando são analisadas as profissões abrangidas no âmbito das Ciências Humanas, quando se pergunta o que visam o psicólogo, o psicanalista, o professor, o pedagogo, o sociólogo, o antropólogo, o historiador, o advogado, o politólogo, para além de suas atividades específicas, ter-se-á como resposta que querem explicitar as condições de existência do homem como sujeito cultural que, como tal, precisa ser formado e cuidado. Buscam entender como o homem se vivencia como sujeito cultural, como lida com sua própria subjetividade, como aprende, como ensina, como se relaciona com as demais pessoas, como quer construir sua cidade.

Assim, o profissional educador, ao desenvolver sua atividade pedagógica, está participando integralmente desse cuidado com a vida. No caso específico do professor, ao exercer sua atividade docente, está investindo na formação dos educandos, cuidando para que possam ter uma existência com maior e melhor qualidade de vida.

Com base nessa premissa, de acordo com a qual o fundamental das profissões é o cuidado com a vida humana em geral, impõe-se concluir que a formação dos profissionais precisa receber igualmente uma atenção muito especial, de tal modo que eles não se transformem apenas em técnicos hábeis em manipular determinadas competências mecânicas. Impõe-se que o seu fazer não se reduza a uma virtus manipulativa das coisas, em geral, e dos seres humanos, em particular. 
A. J. SEVERINO

Os resultados da intervenção profissional estão direta e imediatamente relacionados com o destino dos seres humanos, o que precisa ser explicitado é exatamente o seu valor, ou seja, sua dignidade. Mas para tanto é preciso explicitar qual o sentido que tem essa existência. A explicitação desse sentido é tarefa do conhecimento, seja sob sua perspectiva de análise, pelos recursos da ciência, seja sob a perspectiva da síntese, graças aos recursos da filosofia.

Trata-se, para todo profissional, independente de sua área de especialização, de saber quem é esse ser de cujo cuidado ele é corresponsável. É a dimensão antropológica que deve atravessar o processo de sua formação, no estágio universitário. Se a finalidade da intervenção profissional é o cuidado com as pessoas, pelo suscitar da sensibilidade à condição humana, o trabalho ganha, de pleno, um significado de serviço. Daí a necessidade, para a educação universitária, esclarecer os futuros profissionais para não confundirem os meios com os fins.

Mas ao conhecer a condição humana, o profissional precisa acautelar-se igualmente com o impacto de sua intervenção sobre ela. Isso porque o conhecimento do homem, ou seja, o seu conceito, não é desvinculado de sua condição de dignidade, ou seja, de seu valor. Por isso mesmo, o profissional precisa ter claro para si mesmo até que ponto sua intervenção sobre a realidade natural e sobre a realidade social não está agredindo, violentando essa dignidade humana. Estão agora em pauta as questões éticas e políticas, relacionadas à sensibilidade que cabe ao profissional ter aos valores envolvidos em sua condição. Eis a dimensão axiológica da formação humana, que se desdobra nas dimensões ética e política, e que é imprescindível no espaço/tempo da formação universitária.

Além disso, conhecer o homem e todos os demais elementos do real a ele relacionados supõe sempre um retorno sobre o próprio processo do conhecimento, em geral, e no caso específico do conhecimento em cada ramo científico e tecnológico, em particular. Isso porque, em se tratando de conhecimento, não importam apenas os resultados, mas igualmente o caminho percorrido. Assim, ganha fundamental importância a discussão sobre o método da ciência, em geral, e sobre as metodologias específicas a cada campo científico, em particular. Numa reflexão sobre os processos, sobre os pressupostos e sobre o alcance do conhecimento científico é imprescindível a formação profissional: ela precisa ter sempre uma fundamentação epistemológica. Eis o espaço que cabe à Filosofia ocupar. 


\section{A educação precisa entrar em cena}

A educação é forma imprescindível de cuidado com a vida. É ela que disponibilizará, de forma intencional e sistemática, os recursos proporcionados pelo conhecimento a todos os indivíduos. Pois é com esses recursos que os homens poderão contar para cuidar de sua própria existência. É todo um investimento, compartilhado pela coletividade dos integrantes da espécie para constituírem os sentidos que poderão nortear, construtivamente, a construção histórica de seu próprio destino.

Ainda que emerja e vá se constituindo histórico antropologicamente em continuidade com um processo biológico evolutivo conduzido pelo determinismo natural, vai se instaurando um processo diferenciado pela intervenção de um novo elemento, a subjetividade, qual seja, os sujeitos agentes vão se tornando capazes de interferir eficazmente sobre os próprios mecanismos. Esses novos processos, embora reproduzindo processos naturais em sua concretude material, são redirecionados pela intenção subjetivada dos agentes. Ser redirecionado quer dizer que a finalidade dos atos é posta pelos próprios sujeitos. Com a entrada em cena, por sobre a crosta da biosfera, desta nova camada, a noosfera, com ela se instaura a dimensão cultural. Não é mais apenas a força biológica que vai conduzindo a vida dessa espécie, mas também, com grande eficácia, a força decisiva da própria vontade subjetiva de seus integrantes. De conduzidos vão intervindo também como condutores de sua própria existência.

É por isso também que o processo vital do planeta que até então decorria, ao longo do tempo, como evolução físico-biológica, passa a ter agora uma dimensão histórica. A história se sobrepõe à evolução. Doravante as coisas acontecem não só como resultados de uma evolução natural, mas também em decorrência da intervenção humana. Os resultados objetivados dessa intervenção constituem o que chamamos de cultura.

Mas enquanto a evolução ocorria de forma capilar, silenciosa e bastante harmoniosa, perturbada apenas por acidentes pontuais, a violência só aparecendo incidentalmente, a história é um processo barulhento, conflituoso, violento, uma vez que os agentes, sendo capazes de representar subjetivamente finalidades que, o mais das vezes, não são convergentes. Enquanto os conflitos que opunham entre si os segmentos da vida pré-humana faziam parte integrante do processo do equilíbrio natural da própria vida, os conflitos humanos tornam-se planejados e intencionalizados pelos agentes.

É por isso que se instaura a guerra, sob suas mais variadas formas, onipresente no universo social humano e permanente em toda a temporalidade histórica. Essa nova situação, decorrente da 
intervenção da subjetividade no acompanhamento do processo vital, é a que permite inclusive que compreendamos o que ocorre na natureza, como o demonstra a possibilidade do conhecimento científico. $\mathrm{O}$ conhecimento, atividade subjetiva, elucida e explicita o sentido da realidade objetiva, mas tem grande dificuldade em dar conta de sua própria atividade, geradora da cultura, ou seja, a cultura explica tudo, menos a sua própria especificidade, sua emergência na biosfera.

A ciência é o melhor exemplo desse paradoxo ao não conseguir dar conta do seu próprio processo de desvelar os mecanismos que conduzem a natureza. Ela não consegue explicar a especificidade do processo da emergência da noosfera no seio da biosfera. Sob a condução pelos mecanismos da biosfera, os fins não precisavam ser pré-traçados. Mas sob a condução da noosfera, os fins do existir precisam ser intencionalmente constituídos.

Vale dizer que a natureza se justifica integralmente por si mesma enquanto que a cultura precisa da intervenção humana para se dar uma finalidade. Essa finalidade não está escondida em algum lugar, aguardando apenas ser descoberta ou revelada, ela precisa ser instaurada, elaborada, construída e proposta pelos próprios homens. Uma necessidade absoluta e inexorável que se torna o desafio fundamental para espécie, para que possa sobreviver como tal.

À espécie humana não basta existir por força da natureza, como mero fato físico-biológico, ela precisa se dar uma razão de ser para este existir. Quer queira ou não. Ao renunciar assumir esse compromisso, ela será arrastada por fins arbitrariamente impostos por forças descontroladas da própria noosfera.

\section{A educação e a condução da vida}

A pergunta que se coloca então de modo inexorável: e onde fica a educação? O sucinto esboço de matiz antropológico, que ora sintetizei, permite-nos entender as pretensões da educação e a exigência da filosofia da educação. Enquanto a filosofia se constitui como o esforço da subjetividade para entender, com a maior clareza possível, todo esse processo, a educação se constitui como a tentativa de inserir todos os integrantes da espécie no projeto de construção do humano. Pode-se definir a filosofia como o esforço subjetivo para a compreensão, o mais clara e completamente possível, da própria condição humana.

Por sua vez, em sua particularidade, a filosofia da educação busca entender o lugar, o papel e o sentido da educação no seio dessa condição existencial dos homens. Sob o olhar filosófico, a 
educação aparece como mediação para implementar o projeto humano.

Mas eis aqui um projeto totalmente incompleto. Sem a articulação determinante das leis formadoras da natureza, o homem cultural é um ser contingente, um projeto inacabado, em todas as suas dimensões existenciais.

Daí o empenho e a razão de ser da educação, em seu alcance antropológico, em mediar a implementação desse projeto humanizador, processo que não encontra algo parecido entre outras espécies biológicas. Eis porque a educação, em seu significado antropológico, não é a mesma coisa que ensino, instrução, treinamento. O que está fundamentalmente em pauta é a formação.

Por formação, há que se entender a própria construção do humano, passagem da condição de pura naturalidade para a condição de culturalidade, de construção de autonomia, vinculada à dignidade que deve ser atribuída à pessoa humana, a ser buscada e implementada em todas as nossas práticas, e, consequentemente, na prática educativa. Não se trata de instrução técnica, processo institucionalizado, mas da constituição integral do homem como ente especificamente humano. É o sentido da paideia, processo que alimenta todo o vir-a-ser dos integrantes da espécie. É processo do devir humano como devir humanizador, mediante o qual o indivíduo natural devém um ser cultural, uma pessoa.

Minha ideia de formação é pois aquela do alcance de um modo de ser, mediante um devir, modo de ser que se caracterizaria por uma qualidade existencial marcada por um máximo possível de emancipação, pela condição de sujeito autônomo. Uma situação de plena humanidade. A educação não é apenas um processo institucional e instrucional, seu lado visível, mas fundamentalmente um investimento formativo do humano, seja na particularidade da relação pedagógica pessoal, seja no âmbito da relação social coletiva. A interação docente é mediação universal e insubstituível dessa formação tendo-se em vista a condição da educabilidade do homem (SEVERINO, 2017, p. 64-65).

Sem dúvida, os processos didáticos são mediações práticas importantes, fecundas e valiosas, mas implementar o projeto de humanização não é só habilitar tecnicamente, é transformar o indivíduo natural em pessoa cultural.

\section{O lugar da docência}

Se compreendermos assim o sentido da educação, torna-se mais fácil entendermos o sentido da docência. Pois ela está profundamente articulada a esse sentido do educar. É aqui que entra o 
professor com sua prática pedagógica interventiva! Sob esse pano de fundo dá para entender a necessidade e a relevância da intervenção atuante do professor. $O$ ato de docência é outra mediação de tão fundamental importância que se torna imprescindível. Exatamente porque esse ato é encontro de subjetividades, trata-se a docência de uma relação de intersubjetividade, ou seja, espaço e momento de diálogo entre sujeitos, num diálogo que versa sobre sentidos que, afinal, estamos todos tentando construir e compartilhar. Um diálogo que precisa ser implementado.

Daí a crítica cabível às recorrentes propostas de se substituir o docente-pessoa pelo processo comunicacional de mídia tecnológica, o que vem acontecendo como um mar invadido por maviosos cantos de belas sereias. Mas temos que nos acautelar frente a essa sedução, pois não há como, por essa via, assegurar a dimensão intersubjetiva do processo ensino/aprendizagem. Não bastam imagens reluzentes, palavras pomposas, recursos fantásticos da tecnologia. A inflexão de sentidos só se dá pela troca de olhares, pelos gestos diretos e por densas conversas, só possíveis no encontro interpessoal. O simples disponibilizar informações não assegura a formação.

Sem dúvida, todos sabemos das imensas dificuldades que se põem para o trabalho concreto do professor. A começar por aquelas inerentes ao exercício da própria atividade profissional, à condição de trabalhador assalariado no modo de produção capitalista. A sociedade, de modo geral, sempre valoriza a educação e cobra do professor um desempenho qualificado, como ouvimos, cotidianamente, da mídia, que se apresenta como porta-voz da sociedade, mas também como vemos nos dispositivos legais. Mas, ao mesmo tempo, não Ihe fornece infraestrutura adequada, salários condignos, recursos didáticos pedagógicos, ambientes culturais, todos imprescindíveis para uma intervenção docente eficaz e fecunda. Todas as mediações objetivas necessárias para que sua atuação possa ser eficaz.

O nosso país é reconhecidamente carente em termos educacionais, as políticas públicas da área são assistemáticas e fragmentadas, tudo ainda bem longe de uma real pátria educadora, ainda que se possa identificar avanços importantes, mas que são frutos, o mais das vezes, de iniciativas avulsas e ainda precárias.

A educação é, pois, prática intencional e sistemática com vistas a mediar as demais práticas existenciais dos homens. Visa explicitar os sentidos conceituais dessas práticas, articulando esses sentidos com os sentidos da própria existência humana, razão pela qual precisa explicitar também os valores que qualificam esses sentidos. Sempre em pauta o cuidado com a vida, portanto, a busca de garantia para o existir humano, a cada instante histórico enfrentando as pressões de toda ordem que 
se colocam no seu caminho. O sentido é dado por uma articulação do conceito com o valor, estas duas dimensões da esfera da subjetividade, território do sentido. Percepção epistêmica e vivência sob a sensibilidade valorante.

Mas esse processo que envolve então esclarecimento profundo, sensibilização a valores, referenciais de ação, não pode ficar entregue às pulsões espontâneas nem a forças mecânicas heteronômicas, ele precisa ser um processo sistematizado, planejado e cuidadosamente conduzido. $E$ precisa dispor de mediadores, no caso, os profissionais da educação. Profissionais que precisam ser também cuidadosamente formados, não só mediante a aquisição de habilidades técnicas, mas também de sensibilização a sentidos, lastreando os conceitos esclarecedores e os valores emancipadores, intrinsecamente compromissados com a dignidade humana.

A relação pedagógica se justifica e se legitima na medida em que se dá como essa mediação. E é a qualidade demandada dessa mediação que é o critério para se avaliar a necessidade e a qualidade das instituições educadoras. Por isso mesmo, o que se nos impõe como tarefa nesse front, não é puramente descartar a escola e a atuação dos professores, mas a crítica competente denunciadora dos desvios e desmandos das instituições e das pessoas e o anúncio de novos caminhos para um investimento sistemático e qualificado na preparação de seus profissionais.

\section{O professor e a profissionalidade da intervenção pedagógica}

A ênfase exacerbada a certos aspectos particulares, presentes e parcialmente necessários na configuração do perfil da formação e da atuação do professor, leva a reducionismos que, ao final, acabam por descaracterizar o sentido de sua profissionalidade. Assim, o reconhecimento da presença de um certo "dom natural", de uma certa espontaneidade no exercício da docência, tem levado a uma visão de senso comum de que a ação pedagógica é idêntica à ação maternal.

O senso comum abusa da metáfora da maternagem quando se refere à relação educador/educando. É uma confusão entre as exigências do grande respeito e cuidado que deve reinar na relação entre pais e filhos, em decorrência da dignidade de ambas as partes e da marca de elevado índice de afetividade que a marca. Muitas vezes um apelo exacerbado à afetividade, à emoção acaba por prejudicar a qualidade da relação pedagógica, contaminando-a igualmente com elementos estranhos e nocivos à identidade de cada um e à própria relação.

A relação pedagógica não pode realizar-se apoiando-se em algum espontaneísmo instintivo, 
em dons naturais, ainda que estas formas de energia, sem dúvida, bem humanas, possam colaborar na dinâmica relacional, como forma própria de interação humana. Mas o espontaneísmo, teórico ou prático, é “inimigo" da prática educacional competente e saudável: estamos diante de uma exigência de prática profissional que necessita de referências científicas e de habilidades técnicas ${ }^{3}$. A relação do educador com o educando não se identifica, em que pese o vigor das imagens e das metáforas, com a relação maternal ou paternal.

Nela, a afetividade, característica essencial da espécie, é de outra natureza e tem outro papel a exercer. Isso não quer dizer que a afetividade esteja dela ausente, mas que ela tem aí uma função muito diferenciada. Análogo a esse primeiro reducionismo, constata-se ainda, forte em nossa cultura, a tendência a ver na relação pedagógica, uma relação sacerdotal. Aqui prevalece a identificação com a relação pastoral, de fundo místico e religioso, profundamente arraigada na cultura ocidental e, de modo particular, na cultura brasileira, em decorrência tanto da herança da pedagogia católica como também de uma característica antropológica profundamente marcada por um habitus místico.

Mas o educador não é um sacerdote ou um xamã e o magistério não é um ministério sagrado. Trata-se de se insistir em que a relação pedagógica, profissionalmente conduzida, é uma relação de natureza antropológica, a ser escoimada de qualquer essencialidade religiosa, sob pena de perder sua especificidade (CADERNOS CEDES, 1981; EDUCAÇÃO \& SOCIEDADE, 1999).

Mas, por outro lado, também quando se recorre às ciências e às técnicas, para a superação desses reducionismos pré-científicos, reaparecem outras formas equivocadas de se entender a formação e a atuação do educador. Uma delas é o reducionismo representado por uma exclusiva referenciação filosófica: o filosofismo, que predominou em nossa cultura sob sua configuração essencialista. Tende então a conceber a educação e sua prática a partir de modelagem teóricoconceitual sem vínculos firmes com as realidades históricas concretas, com as contingências das condições do existir real das sociedades e dos indivíduos, levando a uma concepção muito voluntarista

\footnotetext{
${ }^{3}$ Esta uma das razões pelas quais se pleiteia que a formação para a docência seja feita na Universidade, espaço em que, por definição, lida-se com a preparação científica e técnica. Decorre daí a não pertinência da proposta da criação generalizada, no Brasil, dos Institutos Superiores de Educação. Com todos os defeitos e limitações, é no ensino superior que podemos encontrar um mínimo de condições para uma formação mais sólida dos profissionais da educação. Pela ausência de quadros, de recursos e de condições, a nova instância formadora tenderá a reproduzir muito mais o antigo curso normal do que uma efetiva modalidade de ensino superior.
} 
dos processos educacionais. A filosofia, se não se praticar intimamente articulada com uma postura de vigilância crítica, corre sempre o risco de colocar-se num patamar transcendental, desconsiderando a imanência da condição humana e, como tal, desencarna a relação pedagógica da contingência histórica, impondo-lhe aprioristicamente objetivos idealizados inatingíveis.

Mas o recurso às ciências modernas também não evitou graves reducionismos, na medida em que aspectos fundamentais do processo pedagógico são destacados, isolados e hegemonizados. É o caso do psicologismo, sob suas diversas formas de expressão, ao considerar que a relação pedagógica se exaure no relacionamento psíquico; do sociologismo ao reduzir a educação a seus fatores sociais determinantes; do economicismo, ao considerar que são as dinâmicas próprias do processo produtivo os elementos mais importantes a referenciarem o trabalho pedagógico.

Também, intimamente vinculado a esses reducionismos cientificistas, é muito presente em nosso meio o reducionismo tecnicista, ou seja, a crença de que basta o profissional da educação dominar e aplicar competentemente, em sua atividade docente, determinadas habilidades técnicas, para que a relação pedagógica surta seus efeitos, independentemente de qualquer outra significação que não aquela funcionalmente implícita no puro conhecimento objetivo produzido pelas ciências.

O tecnicismo pretende não se envolver com quaisquer referenciações políticas ou filosóficas explícitas, por considerá-las desviantes da finalidade objetiva e pragmática do processo de formação profissional. Só que se esquece, ou não aceita, que tal postura é igualmente uma inegável forma de envolvimento político e filosófico, pois não há como, para os homens, evitarem essa situação. $O$ que ocorre então é uma entrega total a um pragmatismo dogmático, quando não cínico, que faz do profissional um mero executor de tarefas mecânicas, totalmente conduzido por uma ideologia imediatista, sem capacidade de iniciativa e de autonomia crítica frente aos desafios que a prática profissional enfrenta diuturnamente. Como os educadores não vão educar autômatos, mas pessoas complexas em situações ainda mais complexas - o que faz a condição do educador muito diferente da condição de um engenheiro ou de um médico, por exemplo - de pouca valia the serão os seus conhecimentos e habilidades técnicas.

Tanto no que concerne a sua formação como a sua atuação profissional, o educador não se confunde nem com as figuras do pai e da mãe, nem com aquelas do sacerdote, do engenheiro, do cientista, do filósofo, do psicoterapeuta. Ele é um "pedagogo", no sentido originário do termo. Se é verdade que a relação pedagógica tem muitos aspectos em comum com essas outras intervenções, ela não se identifica com nenhuma delas, não se exaure em nenhuma delas. De grande abrangência 
antropológica, a relação pedagógica envolve a totalidade da condição humana, implica todos os aspectos da existência das pessoas, serve-se de todos os seus recursos, mas configura-se numa especificidade própria, a da construção histórico-antropológica dos seres humanos, ao mediar a inserção das novas gerações no complexo universo das mediações do existir histórico-social.

Quando se tem em pauta a condição profissional do educador pode-se afirmar que só será assegurada qualidade a sua atuação se, ao longo dos processos iniciais e continuados de sua formação Ihe for garantido, pelas mediações pedagógicas, um complexo articulado de elementos formativos, produzidos pelo cultivo de sua subjetividade, que traduzam competência epistêmica, técnica e científica, criatividade estética, sensibilidade ética e criticidade política. Será com uma prática guiada por referências dessa natureza, que o profissional da educação poderá exercer sua função educativa no meio social, a partir de sua inserção num projeto educacional.

Portanto, as mediações formadoras precisam equipar-se com recursos que possam dar conta de todas essas dimensões. É por isso que os currículos, como recursos do ensino mediador da formação, precisam incluir componentes do campo filosófico, do campo científico, do campo técnico, do campo artístico, do campo prático, do campo da política, com suas correspondentes atividades práticas.

É pela subjetividade que o homem pode intervir significativamente na objetividade. Por isso mesmo, sua formação, ainda quando voltada para a preparação profissional, pressupõe o cultivo de sua subjetividade. Pois é só com os recursos da ciência e da técnica que ele pode dar conta de seus desafios frente ao saber e ao fazer, no sentido de decodificação do mundo natural e social e da sua intervenção nesse mundo, com vistas a sua adaptação às necessidades da vida.

É só com a sensibilidade ética que poderá legitimar sua ação, respeitando sua própria dignidade de pessoa humana bem como aquela de seus semelhantes, tanto nas relações interindividuais como nas relações sociais mais amplas; só pela sensibilidade estética poderá aproveitar significativamente seus sentimentos e emoções, explorar sua imaginação criadora e relativizar os parâmetros puramente lógico-funcionais da razão natural; só com a criticidade política poderá entender o verdadeiro sentido da cidadania e a ela adequar seu comportamento em sociedade. 


\section{Conclusão}

Isso quer dizer que o que estamos considerando como filosofia uma atividade de reflexão, uma modalidade de exercício da subjetividade cognoscitiva que se envolve exatamente com o delineamento do sentido, articulando e complementando todas as outras modalidades congêneres, num esforço conjunto e convergente com vistas à elucidação do sentido da existência e do esclarecimento de referências para a orientação da prática humana, o grande processo mediador de sua existência.

O humanismo não é uma conclusão do modo metafísico de ser do homem, de sua essência, de sua substancialidade. Mas uma tarefa e uma meta. $O$ homem não tem uma razão de ser, ele pouco pode afirmar quanto a isto, mas lhe cabe dar-se uma razão de ser, ou seja, construir sentidos que possam justificar a continuidade de sua existência. A Filosofia, como de resto todo o conhecimento humano, não se legitimaria se não participasse da tarefa de construir sentido para a existência humana. Se se limitasse a ser um exercício meramente contemplativo, situando-se numa esfera lógica e abstrata, ou se se reduzisse a uma tecnicidade linguística, ela não adquiriria legitimidade. Tornar-se-ia um diletantismo alienante, sem sensibilidade à problemática do existir histórico dos homens.

Aliás, impressiona ver que todos os pensadores, que foram considerados filósofos em nossa tradição cultural, nunca perderam de vista essa destinação de seu pensar, mesmo quando a expressão de seu pensamento não enfocara explicitamente essa temática. Não é outra atitude a se esperar da Filosofia na atualidade, uma vez que não pode deixar de ser sempre igualmente paideia.

Mas por que então tanto o curso formador como o trabalho do pedagogo são tão pouco valorizados. São várias as causas e as origens:

a) pela própria atitude da sociedade como um todo que se acomoda e acaba vendo a educação como mera rotina e não cobra uma oferta qualificada da mesma;

b) pelo Estado, que deveria ser o responsável pela implementação das demandas da sociedade civil, ele que é o representante da sociedade civil, mas que se omite, colocando interesses particulares à frente dos interesses coletivos. Não insere, com a devida prioridade, a educação num seu projeto civilizatório;

c) pelas instituições formadoras que não se preocupam em elaborar o seu projeto 
educacional em que ficasse bem claro o compromisso com a formação à altura do papel que a educação das crianças e as instituições educativas deveriam ter. São igualmente omissas, se burocratizam, se rotinizam;

d) pelos professores incumbidos da tarefa da formação que não equipam com as necessárias ferramentas para seu trabalho profissional de docentes, nem se empenham em qualificar seu desempenho. Não se dão conta que sua postura e envolvimento são retaguarda indispensável de suas aulas;

e) pelos próprios estudantes que não encarnam seu projeto existencial, não se dando conta do papel fundamental e relevante do próprio ofício. Incorporam os estereótipos vigentes no contexto social e acadêmico e até mesmo se autodepreciam;

f) pelos próprios profissionais que, ao assumirem sua atuação na escola desempenham-se descompromissadamente, sem a responsabilidade que o cuidado com a formação das crianças exige intrinsecamente. Não se esmeram no cultivo da própria profissão, sem a sensibilidade que a delicadeza da docência nesse nível exige;

Finalmente, há que se concluir que algumas exigências emergem da situação para o exercício da profissão educadora. São elas: competência, criatividade, eticidade e criticidade. Com efeito, essa atuação precisa ter competência, ou seja, a intervenção educativa não mais pode prescindir dos recursos já alcançados pelo conhecimento científico, pela inovação tecnológica e pela crítica filosófica. Esses são pré-requisitos epistemológicos e práticos. Daí a necessidade insuperável e implacável do estudo sistemático. Não podemos mais ficar na base do espontaneísmo e do senso comum. A pedagogia voltada para as crianças não é maternagem.

Mas ela precisa também ter muita criatividade. As situações que envolvem esse momento da formação infantil são sempre específicas, cada caso é um caso novo, fazendo necessária muita sensibilidade para aguçar a percepção do que está acontecendo. Não cabem respostas mecânicas, bitoladas, rotineiras, automáticas. É preciso desenvolver a capacidade de vivenciar, sentindo. Sentipensar... é um sentimento profundo de empatia. Estamos tratando da sensibilidade estética.

Mas é preciso ainda um senso de solidariedade humana, uma sensibilidade ao outro. Aqui está em pauta a sensibilidade ética, a empatia, o reconhecimento e o respeito pela alteridade. Uma percepção antropológica, pela qual eu reconheço a presença e valor do outro. Uma valoração ética da pessoa do outro, o que gera o decorrente respeito. 
Finalmente, desse profissional é exigida uma leitura permanentemente crítica do mundo, que se constitui pela capacidade de decodificar as artimanhas ideológicas do poder, além daquelas que se disfarçam no saber e no fazer. A ideologia atua como um nevoeiro que embaça nossa visão das coisas e das situações, invertendo o sentido delas, apresentando mentiras como verdades, enganandonos profundamente. Está em causa aqui a sensibilidade política, pela qual nos tornamos capazes de aquilatar qual é o verdadeiro interesse pelo qual devemos lutar, superando o egoísmo pessoal e de grupo e nos envolver tão somente na conquista de objetivos de interesse universal, interesses de todas as pessoas.

\section{Referências}

BRANDÃO, C. R. Nós, os humanos: do mundo à vida, da vida à cultura. São Paulo: Cortez, 2015.

CEDES. A formação do educador em debate. Cadernos Cedes. São Paulo/Campinas, Cedes/Cortez/Autores Associados, n. 2, 1981.

CEDES. Formação de profissionais da educação: políticas e tendências. São Paulo/Campinas. Educação \& sociedade, n. 68, Especial, dez. 1999.

CHARDIN, T. O fenômeno humano. Porto: Livraria Tavares Martins, 1955.

HARARI, Y. N. Sapiens: uma breve história da humanidade. 24. ed. Porto Alegre: L\&PM Editores, 2017. REIS, L. R. Entre o sentido do cuidado e o cuidado do Sentido: dispositivos formativos, controles e sinuosidades de um novo individualismo na cultura contemporânea. 2015. 160p. Dissertação (Mestrado em Educação) - Universidade Federal da Bahia, Salvador, 2015.

SEVERINO, A. J. Educação, sujeito e história. São Paulo: Olho d’Água, 2001. . Filosofia na formação profissional. São Paulo: Arte Livros, 2017. 